\title{
Prevalence of Glucose-6-Phosphate Dehydrogenase Deficiency among Steady-State Sickle Cell Disease Children at University of Ilorin Teaching Hospital, Ilorin
}

\author{
Surajudeen Oyekunle Ogunkanbi', Olanrewaju Timothy Adedoyin², Sikiru Abayomi Biliaminu ${ }^{3}$, \\ Samuel Kolade Ernest ${ }^{2}$ \\ ${ }^{1}$ Paediatrics Department, Abuja Clinics Limited, Abuja, Nigeria \\ ${ }^{2}$ Department of Paediatrics, University of Ilorin Teaching Hospital, Ilorin, Nigeria \\ ${ }^{3}$ Department of Chemical Pathology, UITH, Ilorin, Nigeria \\ Email:ogos4u@gmail.com,ooadedoyin@yahoo.com,drbiliaminu@gmail.com,skernest@unilorin.edu.ng
}

How to cite this paper: Ogunkanbi, S.O., Adedoyin, O.T., Biliaminu, S.A. and Ernest, S.K. (2019) Prevalence of Glucose-6Phosphate Dehydrogenase Deficiency among Steady-State Sickle Cell Disease Children at University of Ilorin Teaching Hospital, Ilorin. Open Journal of Pediatrics, 9, 29-38.

https://doi.org/10.4236/ojped.2019.91004

Received: October 12, 2018

Accepted: January 20, 2019

Published: January 23, 2019

Copyright (๑) 2019 by author(s) and Scientific Research Publishing Inc. This work is licensed under the Creative Commons Attribution International License (CC BY 4.0).

http://creativecommons.org/licenses/by/4.0/

\begin{abstract}
Background: Both glucose-6-phosphate dehydrogenase (G6PD) deficiency and sickle cell disease (SCD) are prevalent in malaria-endemic regions. Controversy however persists as to whether G6PD deficiency is commoner in SCD subjects compared with the general population. Co-existence of the enzyme-deficient state with a chronic haemolytic disorder, like SCD, could potentially predispose to fatal haemolytic episodes. There is however a dearth of paediatric studies on this subject. Aims and Objectives: To determine the prevalence and demographic determinants of G6PD deficiency in children with SCD. Methods: Red cell G6PD activity was determined in 115 steady-state sickle cell disease children aged 0.5 - 17 years, in steady state and equal number of age \& gender-matched non-SCD controls using the quantitative method. A measured G6PD activity of $<6.97 \mathrm{U} / \mathrm{gHb}$ defined G6PD deficiency while values $\geq 6.97 \mathrm{U} / \mathrm{gHb}$ were regarded as normal. Data were analysed using SPSS version 20. Statistical analyses done include chi-square, student $t$-test and ANOVA. For all statistical analyses, $p$ values less than 0.05 were considered significant. Results: There were $64(55.7 \%)$ males and 51 (44.3\%) females in each of the arms of the study. The mean age of the study population was $8.4 \pm 4.7$ years. Seven of the subjects were G6PD-deficient giving a prevalence of $6.1 \%$ which was not significantly different from the $7.0 \%$ obtained in the controls $(p=0.789)$. G6PD deficiency was more frequently encountered in the older age groups although the difference was not statistically significant $(p=0.438)$. Similarly, mean G6PD activity was highest
\end{abstract}


in the under-5 age-group compared to the older age-groups analysed ( $\mathrm{p}=$ 0.573). The condition was also commoner in the males than females although the difference did not attain statistical significance $(p=0.897)$. Conclusions: The prevalence of G6PD deficiency among SCD children was 6.1\%. The condition is marginally commoner in males and older children.

\section{Keywords}

Prevalence, G6PD Deficiency, Steady-State, Sickle Cell Disease

\section{Introduction}

Glucose-6-phosphate dehydrogenase (G6PD) deficiency, like sickle cell disease (SCD), is prevalent in malaria-endemic regions such as Africa (especially sub-Saharan Africa), Asia and the Mediterranean regions [1]. This has been attributed to the partial protection this condition offers against severe malaria, thus conferring a survival advantage on sufferers residing in malaria-endemic regions [1] [2]. Acquired in an X-linked recessive fashion, G6PD deficiency is the commonest enzymopathy worldwide affecting up to 400 million persons [3]. The prevalence figures across the West African sub-region range from about $8.5 \%$ in Ghana [4] to $31 \%$ in Burkina Faso [5], with the latest prevalence estimate for Nigeria put at 8.6\% [4] [5] [6]. Glucose-6-phosphate dehydrogenase catalyzes a key step in the pentose-phosphate pathway critical to the maintenance of glutathione in the reduced state [7]. The reduced glutathione in turn neutralizes agents that potentially oxidize either haemoglobin or other components of the RBC membrane [8]. The enzyme is thus vital to the defence of red cells against oxidative stress, especially in children with SCD, known to face increased oxidative challenge [9] [10]. The commonest manifestation of the condition is recurrent, acute (and often life-threatening) haemolytic episodes, which commonly follows exposure to a wide range of oxidant medications or infectious agents [3] [7].

In view of the relatively high prevalence figures of SCD and G6PD deficiency in malaria-endemic areas of the world [1] [6], several studies have been done, attempting to unravel the possible interactions that may exist between these two inherited haematologic conditions. As a follow up to the findings of a number of published work, documenting the protective effect of both conditions against malaria, several other studies have been done comparing the prevalence of G6PD deficiency in SCD subjects with that in the general population [11]-[16]. Findings on this subject have been divergent with various studies reporting higher, lower and almost equal prevalence of G6PD deficiency in the SCD sub-population, compared with the general population [13] [17] [18] [19]. Similarly, the impact of co-existing G6PD deficiency on survival of SCD subjects has generated significant controversy. A number of studies have demonstrated a rising age-stratified prevalence of G6PD deficiency with advancing age in SCD 
children, suggesting a possible survival advantage associated with the enzyme deficiency state. These finding was however not corroborated in some other studies [19] [20].

Worthy of note however is the fact that nearly all of the available published work on this subject recruited predominantly adult subjects with only a handful of paediatric subjects included. Specifically, this author is unaware of any paediatric study on the prevalence of G6PD deficiency in SCD subjects, especially on the African continent. Wholesale adoption/extrapolation of findings from such adult-based studies for use in paediatrics may be misleading. This study therefore sought to provide a paediatric perspective on the above subjects. The aim of the study was to determine the prevalence and demographic determinants of G6PD deficiency in children with SCD.

\section{Methods}

\subsection{Subjects}

This was a comparative cross-sectional study, conducted in the Paediatric Sickle Cell Disease Clinic of the University of Ilorin Teaching Hospital (UITH), Ilorin. Subjects were known SCD children aged 6 months to 17 years, in steady state, while clinically stable, age- and gender-matched non-SCD peers of the subjects were recruited as controls. The study was carried out over a six-month period; between July 2012 and January 2013. A total of 115 subjects and equal number of controls were recruited for the study. Children transfused in the preceding three months and those with severe anaemia were excluded from the study. Ethical clearance was obtained from the Ethics and Research Committee of UITH, Ilorin and an informed consent (and assent where applicable) obtained from parents of eligible children.

Eligible children were recruited consecutively for the study using a semi-structured questionnaire.

\subsection{Laboratory Procedure}

Four mls of blood was collected from all enrolled subjects and controls by venepuncture using aseptic procedure. This was divided equally into two ethylene diamine tetra-acetate (EDTA) bottles. The first EDTA sample was used for G6PD activity assay, while the second sample was used for Haemoglobin electrophoresis. Assay for G6PD activity was done using the quantitative in-vitro test kit by RANDOX ${ }^{\odot}$ Laboratories Limited (Ardmore Diamond Road, Crumlin, Co. Antrim, United Kingdom, BT 294 QY). Its principle is based on the reduction of NADP+ by G6PD present in red blood cells. The NADPH generated fluoresces under ultraviolet light at a wave length of $340 \mathrm{~nm}$. Enzyme activity is determined by the rate of absorbance change [21] [22]. A measured G6PD activity of $<6.97 \mathrm{U} / \mathrm{gHb}$ defined G6PD deficiency while values $\geq 6.97 \mathrm{U} / \mathrm{gHb}$ were regarded as normal [22]. Haemoglobin genotype was determined using standard electrophoretic technique in an alkaline medium. All samples were refrigerated 
immediately after collection at $4^{\circ} \mathrm{C}-8^{\circ} \mathrm{C}$ and analysed within 24 hours.

\subsection{Data Analysis}

Data was analysed using the IBM SPSS version 20.0 (IBM corporation, Virginia, USA) software package. The Chi-square test was used to identify significant differences in the categorical variables while the Student's t test and the analysis of variance (ANOVA) test were used, as appropriate, to identify such differences in the continuous variables. Yates correction and Fishers exact tests were deployed as necessary. For all statistical analyses, $p$ values less than 0.05 were considered significant.

\section{Results}

One hundred and fifteen SCD patients (subjects) and equal number of controls were recruited for the study. One hundred and five (91.3\%) of the subjects had haemoglobin genotype SS, while the remaining 10 (8.7\%) had genotype SC. Similarly, $108(93.9 \%)$ of the controls had haemoglobin genotype AA while 4 (3.5\%) and 3 (2.6\%) had genotypes AS and AC, respectively. The mean age $( \pm \mathrm{SD})$ among the subjects was $8.0 \pm 4.6$ years while the corresponding value in the controls was $8.0 \pm 4.7$ years. As shown in Table 1, 33 (28.7\%) of the subjects were within the under-5 age group while $14(12.2 \%)$ were aged 15 years and above. Sixty-four of the subjects (55.7\%) were males while $51(44.3 \%)$ were females.

Most (96.5\%) of the subjects were of Yoruba descent, comparable to the finding among the controls, $94.8 \%$ of whom were also Yoruba by tribe $\left(x^{2}=1.018, \mathrm{df}=\right.$ 2, $p=0.601$ ). Similarly, most of the families in both groups belonged to socio-economic classes II, III \& IV.

\subsection{Prevalence of Glucose-6-Phosphate Dehydrogenase Deficiency in the Study Population}

Seven of the subjects (6.1\%) were G6PD-deficient while eight (7.0\%) of the controls were found to be G6PD-deficient. Subjecting this distribution to the Chi-square test, there was no significant difference in the prevalence of G6PD deficiency among the 2 groups $\left(x^{2}=0.071, \mathrm{df}=1, p=0.789\right)$. The G6PD-deficient in both groups were homozygous for $\mathrm{Hb}$ genotype $\mathrm{S}$ and $\mathrm{A}$

Table 1. Age and gender distribution of the subjects.

\begin{tabular}{cccc}
\hline \multirow{2}{*}{ Age group (years) } & Male & Female & \multirow{2}{*}{ Total (\%) } \\
\cline { 2 - 3 } & 20 & 13 & $33(28.7)$ \\
$0.5-4$ & 20 & 19 & $39(33.9)$ \\
$5-9$ & 18 & 11 & $29(25.2)$ \\
$10-14$ & 6 & 8 & $14(12.2)$ \\
Total (\%) & $64(55.7)$ & $51(44.3)$ & $115(100)$ \\
\hline
\end{tabular}


respectively. However, the mean $( \pm \mathrm{SD}) \mathrm{G} 6 \mathrm{PD}$ activity among the subjects was $20.56 \pm 10.04 \mathrm{U} / \mathrm{gHb}$ which was significantly lower than $24.05 \pm 10.85 \mathrm{U} / \mathrm{gHb}$ obtained in the controls $(t=-2.525, \mathrm{df}=114, p=0.007)$.

\subsection{Gender Distribution of Glucose-6-Phosphate Dehydrogenase Deficiency}

Table 2 shows the distribution of glucose-6-phosphate dehydrogenase activity and status by gender in the study population. The enzyme deficiency status was commoner among the males than females, in both the subjects and controls. Using the Fisher's exact test, the male predominance in both groups was, however, not of statistical significance. Similarly, the mean $( \pm S D)$ G6PD activity in the males was higher than the corresponding value in the females, in both groups. These differences were however not of statistical significance $(p=0.897$ and 0.215 in the subjects and controls, respectively).

\subsection{Age Distribution of Glucose-6-Phosphate Dehydrogenase Deficiency}

Figure 1 shows the distribution of G6PD deficiency across the various age strata.

Table 2. Distribution of glucose-6-phosphate dehydrogenase status and activity by gender in the study population.

\begin{tabular}{ccccc}
\hline Parameter & \multicolumn{2}{c}{ Subjects } & \multicolumn{3}{c}{ Controls } \\
\hline Gender & Male & Female & Male & Female \\
\hline Number & 64 & 51 & 64 & 51 \\
G6PD-deficient & 4 & 3 & 6 & 2 \\
$\%$ & 6.3 & 5.9 & 9.4 & 3.9 \\
$p$ value & & 0.625 & & 0.223 \\
Mean $( \pm$ SD) G6PD & $21.36 \pm 10.19$ & $19.55 \pm 9.86$ & $25.04 \pm 10.44$ & $23.72 \pm 11.19$ \\
activity & & 0.961 & & 0.925 \\
$t$ test & & 0.897 & & 0.215 \\
$p$ value & & & &
\end{tabular}

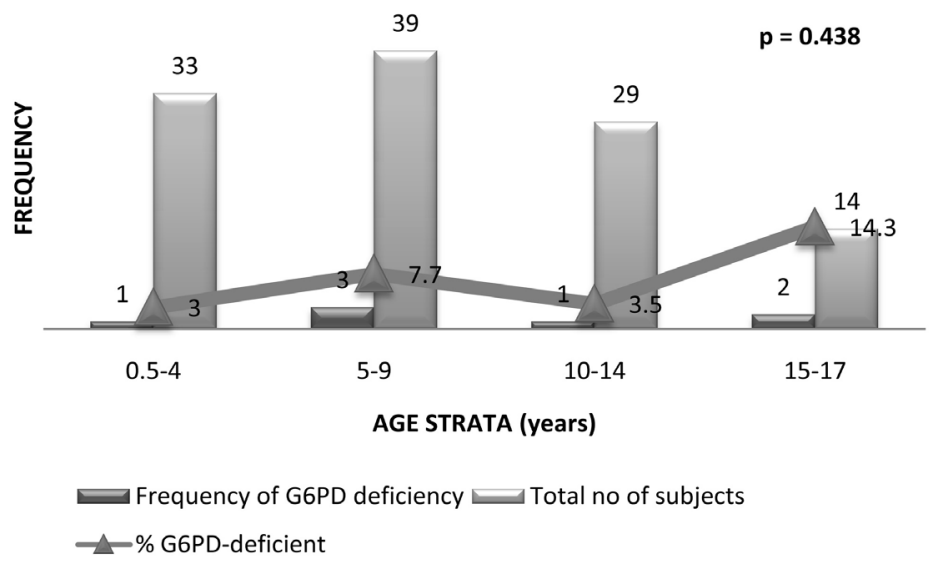

Figure 1. Age distribution of glucose-6-phosphate dehydrogenase deficiency among the subjects. 
The highest proportion of G6PD deficiency (14\%) was found in subjects 15 yrs and above, while subjects under 5 years of age had the lowest proportion (3\%) of those who were G6PD-deficient. The differences across the various age groups was however not statistically significant $\left(x^{2}=2.715, \mathrm{df}=3, \mathrm{p}=0.438\right)$.

Similarly, as depicted in Figure 2, the under-5 age group had the highest mean $( \pm \mathrm{SD}) \mathrm{G} 6 \mathrm{PD}$ activity $(22.65 \pm 9.62 \mathrm{U} / \mathrm{gHb})$ while the age group $10-15$ years had the lowest $(19.55 \pm 8.55 \mathrm{U} / \mathrm{gHb})$. The differences in these values across the groups also did not attain statistical significance ( $\mathrm{F}$ stat $=0.669, \mathrm{df}=3, p=$ $0.573)$.

\section{Discussion}

The prevalence of G6PD deficiency among the SCD population in this study was $6.1 \%$. This value is lower than that reported by earlier studies, all of which recruited predominantly adult subjects. In Nigeria, studies by Bienzle et al. [18] and Egesie et al. [23] had earlier reported prevalence of $16 \%$ and $18.5 \%$ respectively. Similarly, prevalences ranging between 21.6 to as high as $45 \%$, had emanated from studies conducted in SCD subjects in other parts of Africa [11] [13] [17]. Naylor et al. and Piomelli et al. in studies conducted in the USA also reported much higher values than that found in this study. The substantial differences between the prevalence figure from this study and earlier studies may be due, largely, to the marked differences in the study population as alluded to earlier. Furthermore, the deployment of the less reliable semi-quantitative test in some of the cited studies [11], as against the quantitative estimation used in this study, as well as the relatively small SCD population studied by some of the earlier authors, could also have contributed to the disparity observed [11] [17]. Geographical factor is yet another possible contributor. Ilorin, in the North-Central region of Nigeria, has peculiar climatic indices, which are quite distinct from what obtains even in Ibadan, located within the same country. Some of these may result in differing malaria endemicity pattern, a key factor known to influence the prevalence of G6PD deficiency [2] [24].

However, allowing for the probable influence of the factors mentioned above,

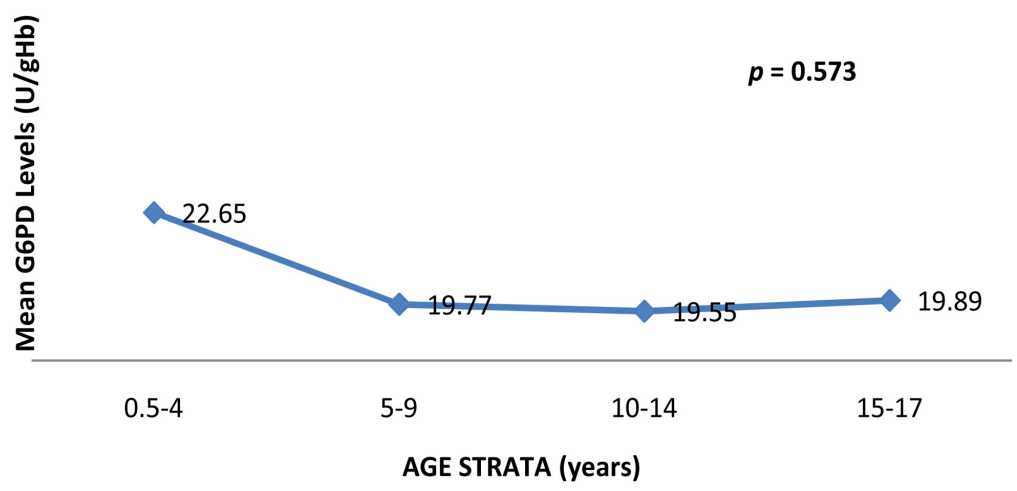

Figure 2. Variations in mean glucose-6-phosphate dehydrogenase activity with age among the subjects. 
juxtaposing the prevalence from this study with that from earlier studies, done predominantly in adults tend to paint a picture of increasing G6PD deficiency prevalence with advancing age in SCD subjects. This, on face value, would suggest that a sizable proportion of G6PD-deficient SCD children are surviving into adulthood, raising the likelihood of G6PD-deficiency conferring a survival advantage on SCD subjects. A critical appraisal of the age-stratified prevalence of G6PD-deficiency among SCD patients, in this study, also showed a near-steady rise in the proportion of G6PD-deficient subjects with advancing age. The lowest prevalence (3.0\%) was seen in the under-5 age group while the highest (14.3\%) was found in subjects aged 15 to 17 years. The distribution of mean G6PD activity across the age groups also mirrored this pattern, with the highest mean enzyme activity found in the under-5 age-group and the lowest in those above 15 years. The difference in the proportion of G6PD subjects between the age groups was however not of statistical significance (possibly due to the much lower number of recruited subjects aged 15 years and above). This finding is identical to that reported by Simpore et al. [17] in Burkina Faso. A possible explanation for this trend is the well documented protection G6PD deficiency is known to offer against malaria. In a malaria-endemic region like Nigeria, this protective effect could imply less frequent intercurrent malaria episodes and malaria-precipitated vaso-occlusive crises which might ultimately translate into a survival advantage for enzyme-deficient persons. However, the relatively low population of G6PD-deficient subjects found in this study, as well as the fact that the difference in the proportion of enzyme-deficient subjects across the various age groups did not assume statistical significance, indicates the need for further studies before such deductions can be validated. This is especially so, bearing in mind the propensity of enzyme-deficient persons to equally develop fatal haemolytic episodes when exposed to oxidants. A number of other studies also failed to demonstrate this trend.

A comparison of G6PD deficiency prevalence in the SCD population with that in the controls revealed a marginally, but statistically insignificant, higher prevalence $(6.1 \%$ in the SCD subjects, $7.0 \%$ in the controls) in the latter group. Although the values are much lower, possibly due to the reasons earlier highlighted, the overall pattern is identical to that reported in earlier studies [12] [15] [18] [19]. This is hardly surprising, considering the fact that the genes involved in these conditions are located on different chromosomes, hence are expected to assort independently. In contrast to the above, findings from a number of other studies [11] [13] [17], many of which were also done within the West African sub-region showed significantly higher prevalence of G6PD deficiency in the SCD population compared with the controls. This disparity might have stemmed from methodological differences as a larger pool of SCD subjects was recruited and the more reliable quantitative G6PD assay was deployed in this study. However, the factors responsible for the difference in the findings from this study and that by Diop et al. [13], who also recruited over 100 SCD subjects and controls, and made use of quantitative G6PD assay method are not imme- 
diately apparent, but could be linked to geographical variations.

Glucose-6-phosphate dehydrogenase deficiency was commoner in the males than females, both in the SCD and control populations. This is to be expected a priori, in view of the $\mathrm{X}$-linked recessive inheritance of the disease. Female offsprings of a G6PD-deficient father would all be carriers (heterozygotes) of the trait, with a variable range of G6PD activity, while each male offspring of a carrier or affected (homozygote) mother has a $50 \%-100 \%$ chance of being G6PD-deficient [21] [25]. The difference in sex prevalence in this study was, however, not of statistical significance. Similarly, there was no significant difference in the mean G6PD activity between the males and the females, though values in the males were marginally higher than that in the females. This trend is supported by findings from a number of other studies [17] [19], including a recent one conducted by Obasa et al. [26] within the same study site, but in the neonatal age group. The findings of Kaplan et al. [27] in neonatal studies done in the USA, however runs parallel to the above with a higher G6PD deficiency prevalence found in females compared to males, though the difference was not statistically significant. In addition to the fact that this finding is contrary to what would be expected of an X-linked disorder, the wide variations existing between this study population and that of Kaplan [27] may not allow for a sound comparison.

\section{Conclusion}

There is no significant difference between the prevalence of G6PD deficiency among SCD and non-SCD populations. The enzyme-deficient status is however marginally commoner among the non-SCD, males and the older subjects. Children with suggestive features/history, irrespective of $\mathrm{Hb}$ genotype, should be offered prompt testing and counselling to forestall fatal haemolytic episodes.

\section{Conflicts of Interest}

The authors declare no conflicts of interest regarding the publication of this paper.

\section{References}

[1] Greene, LS. (1993) G6PD Deficiency as Protection against Falciparum Malaria: An Epidemiologic Critique of Population and Experimental Studies. Yearbook of Physical Anthropology, 36, 153-178. https://doi.org/10.1002/ajpa.1330360609

[2] Guindo, A., Fairhurst, R.M., Doumbo, O.K., Wellems, T.E. and Diallo, D.A. (2007) X-Linked G6PD Deficiency Protects Hemizygous Males But Not Heterozygous Females against Severe Malaria. PLOS Medicine, 4, e66. https://doi.org/10.1371/journal.pmed.0040066

[3] Frank, J.E. (2005) Diagnosis and Management of G6PD Deficiency. American Family Physician, 72, 1277-1282.

[4] Burchard, G.D., Browne, E.N., Sievertsen, J., May, J. and Meyer, C.G. (2001) Spleen Size Determined by Ultrasound in Patients with Sickle Cell Trait, HbAC Trait and 
Glucose-6-phosphate-dehydrogenase Deficiency in a Malaria Hyperendemic Area (Ashanti Region, Ghana). Acta Tropica, 80, 103-109. https://doi.org/10.1016/S0001-706X(01)00157-7

[5] Meissner, P.E., Coulibaly, B., Mandi, G., Mansmann, U., Witte, S., Schiek, W., et al. (2005) Diagnosis of Red Cell G6PD Deficiency in Rural Burkina Faso: Comparison of a Rapid Fluorescent Enzyme Test on Filter Paper with Polymerase Chain Reaction Based Genotyping. British Journal of Haematology, 131, 395-399. https://doi.org/10.1111/j.1365-2141.2005.05778.x

[6] Carter, N., Pamba, A., Duparc, S. and Waitumbi, J.N. (2011) Frequency of Glucose-6-Phosphate Dehydrogenase Deficiency in Malaria Patients from Six African Countries Enrolled in Two Randomized Anti-Malarial Clinical Trials. Malaria Journal, 10, 241. https://doi.org/10.1186/1475-2875-10-241

[7] Pamba, A., Richardson, N.D., Carter, N., Duparc, S., Premji, Z., Tiono, A.B., et al. (2012) Clinical Spectrum and Severity of Hemolytic Anemia in Glucose 6-Phosphate Dehydrogenase-Deficient Children Receiving Dapsone. Blood, 120, 4123-4133. https://doi.org/10.1182/blood-2012-03-416032

[8] Segel, G.B. (2004) Enzymatic Defects. In: Berhman, R.E., Kliegman, R.M., Jenson, H.B., Eds., Nelson Textbook of Paediatrics, 17th Edition, Saunders, Philadelphia, 1636-1637.

[9] Rank, B.H., Carlsson, J. and Hebbel, R.P. (1985) Abnormal Redox Status of Membrane-Protein Thiols in Sickle Erythrocytes. Journal of Clinical Investigation, 75, 1531-1537. https://doi.org/10.1172/JCI111857

[10] Hebbel, R.P., Eaton, J.W., Balasingam, M. and Steinberg, M.H. (1982) Spontaneous Oxygen Radical Generation by Sickle Erythrocytes. Journal of Clinical Investigation, 70, 1253-1259. https://doi.org/10.1172/JCI110724

[11] Lewis, R.A., Kay, R.W. and Hathorn, M. (1966) Sickle Cell Disease and Glucose-6-Phosphate Dehydnogenase. Acta Haematologica (BaseI), 36, 399-411. https://doi.org/10.1159/000209420

[12] Lambotte, C., Durenne, J.M. and Israel, E. (1968) La deficience en glucose 6-phosphate dehydnogenase au Congo. Annale de la Societe Belge de MedecineTropicale, 48, 473-494.

[13] Diop, S., Sene, A., Cisse, M., Toure, A.O., Sow, O., Thiam, D., et al. (2005) Prevalence and Morbidity of G6PD Deficiency in Sickle Cell Disease in the Homozygote. Dakar Médical, 50, 56-60.

[14] Gibbs, W.N., Wardle, J. and Serjeant, G.R. (1980) G6PD Deficiency and Homozygous Sickle Cell Disease in Jamaica. British Journal of Haematology, 45, 73-80. https://doi.org/10.1111/j.1365-2141.1980.tb03812.x

[15] Naylor, J., Rosenthal, I., Grossman, A., Schulman, I. and Hsia, D.Y. (1960) Activity of Glucose-6-Phosphate Dehydrogenase in Erythrocytes of Patients with Various Abnormal Hemoglobins. Pediatrics, 26, 285-292.

[16] Piomelli, S., Reindonf, C.A., Arzanian, M.T. and Corash, L.M. (1972) Clinical and Biochemical Interactions of Glucose-6-Phosphate Dehydnogenase Deficiency and Sickle-Cell Anaemia. New England Journal of Medicine, 287, 213-217. https://doi.org/10.1056/NEJM197208032870502

[17] Simpore, J., Damintoti, K., Sawadogo, L., Binet, S., Nitiema, H., Ouedraogo, P., et al. (2007) Glucose-6-Phosphate Dehydrogenase Deficiency and Sickle Cell Disease in Burkina Faso. Pakistan Journal of Biological Sciences, 10, 409-414. https://doi.org/10.3923/pjbs.2007.409.414

[18] Bienzle, U., Sodeinde, O., Effiong, C.E. and Luzzatto, L. (1975) G6PD Deficiency 
and Sickle Cell Anemia: Frequency and Features of the Association in an African Community. Blood, 46, 591-597.

[19] Bouanga, J.C., Mouélé, R., Préhu, C., Wajcman, H., Feingold, J. and Galactéros, F. (1998) Glucose-6-Phosphate Dehydrogenase Deficiency and Homozygous Sickle Cell Disease in Congo. Human Heredity, 48, 192-197. https://doi.org/10.1159/000022801

[20] Steinberg, M.H., West, M.S., Gallagher, D. and Mentzer, W. (1988) Cooperative Study of Sickle Cell Disease: Effects of Glucose-6-Phosphate Dehydrogenase Deficiency upon Sickle Cell Anemia. Blood, 71, 748-752.

[21] Ainoon, O., Alawiyah, A., Yu, Y.H. and Cheong, S.K. (2003) Semi-Quantitative Screening Test for G6PD Deficiency Detects Severe Deficiency but Misses a Substantial Proportion of Partially Deficient Females. Southeast Asian Journal of Tropical Medicine and Public Health, 34, 404-405.

[22] Lohr, G.W. and Waller, H.D. (1974) Glucose-6-Phosphate Dehydrogenase. Methods of Enzymatic Analysis, 2, 636-643. https://doi.org/10.1016/B978-0-12-091302-2.50026-8

[23] Egesie, O.J., Mamman, A.I., Joseph, D.E., Durosinmi, M.A., Agaba, I.E., Egesie, U.G., et al. (2005) Glucose-6-Phosphate Dehydrogenase (G6PD) Deficiency in Patients with Sickle Cell Anaemia in Jos, North Central Nigeria. Journal of Medicine in the Tropics, 7, 20-25.

[24] Bienzle, U., Ayeni, O., Lucas, A.O. and Luzzatto, L. (1972) Glucose-6-Phosphate Dehydrogenase and Malaria. The Lancet, 1, 107-110.

https://doi.org/10.1016/S0140-6736(72)90676-9

[25] Kaplan, M., Beutler, E., Vreman, H., Hammerman, C., Levy-Lahad, E. and Rebaum, P. (1999) Neonatal Hyperbilirubinaemia in Glucoe-6-Phosphate Dehydrogenase Deficient Heterozygotes. Pediatrics, 104, 68-74. https://doi.org/10.1542/peds.104.1.68

[26] Obasa, T.O., Mokuolu, O.A. and Ojuawo, A. (2011) Glucose-6-Phosphate Dehydrogenase Levels in Babies Delivered at the University of Ilorin Teaching Hospital. Nigerian Journal of Paediatrics, 38, 165-169. https://doi.org/10.4314/njp.v38i4.72277

[27] Kaplan, M., Herschal, M., Hammerman, C., Hoger, J.D. and Stevenson, D.K. (2004) Hyperbilirubinaemia among African-American Glucose-6-Phosphate Dehydrogenase Deficient Neonates. Journal of Pediatrics, 114, e213-e219. https://doi.org/10.1542/peds.114.2.e213 